\title{
Effect of critical thinking training on the psychiatric nurses' job satisfaction
}

\author{
Abbas Heydari ${ }^{1}$, Parvaneh Soodmand ${ }^{2}$, Ali Meshkinyazd ${ }^{3}$
}

\author{
Journal of Research \& Health \\ Social Development \& Health Promotion \\ Research Center \\ Vol. 6, No. 5, Nov \& Dec 2016 \\ Pages: 479- 486 \\ DOI: 10.18869/acadpub.jrh.6.5.479 \\ Original Article
}

1. Evidence-Based Caring Research Center, Department of MedicalSurgical Nursing, School of Nursing and Midwifery, Mashhad University of Medical Sciences, Mashhad, Iran

2. Department of Nursing, School of Nursing and Midwifery, Mashhad University of Medical Sciences, Mashhad, Iran

3. Correspondence to: Department of Nursing, School of Nursing and Midwifery, Mashhad University of Medical Sciences, Mashhad, Iran

Email: MeshkinA1@mums.ac.ir

Received: 20 Oct 2013

Accepted: 5 Mar 2014

How to cite this article: Heydari A, Soodmand P, Meshkinyazd A. Effect of critical thinking training on the psychiatric nurses' job satisfaction. J Research \& Health2016; 6(5): 479- 486.

\begin{abstract}
Nurses are of the most important staff in health systems. Nurses' job satisfaction is an important issue in the nursing management. The aim of this study is to determine the effect of critical thinking training on the nurses of psychiatric wards' job satisfaction. In this study, 54 participants were divided into two groups by random allocation. Brayfield \& rothe job satisfaction questionnaire was used as the scale for data collection in three stages; before intervention, 1 month, and 2 month after the intervention. This intervention included two 6 hours sessions of critical thinking training, which were carried out with an interval of one week. The results of this study reveal that the mean score of the job satisfaction in the experimental group in pre-intervention stage (62.5 \pm 7.6$)$ has been increased to $66.8 \pm 6.4$ one month after intervention, and to $69.5 \pm 6.9$ in the third stage (two month after the intervention), which is significantly more than the control group. The job satisfaction of the control group decreased admirably one month and two month after the intervention stage. It can be concluded that critical thinking training is an effective method to increase the job satisfaction, it is suggested that the managers consider it to increase the nurses' job stress.
\end{abstract}

Keywords: Critical Thinking, Job, Nurse, Satisfaction

\section{Introduction}

In recent years, much attention has been drawn to job satisfaction as a key concept in nursing research, due to its extensive and remarkable effect on nurses, patients, hospitals and the nursing profession [1]. Job satisfaction is a positive and emotional state resulting from individual's assessment of their job or job experience [2]. Since nurses have a major role in providing healthcare services in hospitals, factors affecting their job satisfaction directly affect the quality of care provided; therefore, it has always been a vital subject to study [3]. Currently, the large number of nurses leaving the profession has become a major global concern. Studies recognize the lack of job satisfaction as the most important cause, such that about one third of nurses in England and one fifth in America were willing to leave the profession [4]. Many studies have been conducted on job satisfaction in nurses, and all confirm it particular importance in nursing. In a study by Vaghar Seidin et al., $88.1 \%$ of nurses were relatively dissatisfied with their job, and only $1.6 \%$ were satisfied [5]. Akhtari-Shojaee et al. reported that $72 \%$ of nurses were dissatisfied with their job [6]. 
Quoting Saneie, Veis Moradi reports that the majority of nurses $(54.1 \%)$ in internal- surgery departments had poor level of job satisfaction [7]. Studies published in various countries regarded job satisfaction as an important predictor of nurses' absenteeism, occupational burnout, turnover, and turnover intension [8]. Attention must be paid to the importance of job satisfaction in high-stress departments, including psychiatric department. Working in psychiatric department is stressful and dangerous for nurses because they are exposed to a constant stream of tiring stressful stimuli $[9,10]$. Various studies have confirmed that half of the psychiatric nurses suffer excessive levels of stress and emotional exhaustion [11]. Studies indicate that, in addition to health risks for nurses, stress hugely affects their ability to cope with such risks [12]. Given the key role of nurses in assessment, care and meeting psychiatric needs of patients, attention to and attempt to raise their job satisfaction is essential because, with greater motivation, they can provide better and more effective services and remain in their job. Since stress is an influential factor in job satisfaction of nurses; it is necessary for psychiatric nurses to have knowledge of relaxation and stress control. Therefore, stress management programs can probably be beneficial in improving their job satisfaction, and consequently, maintaining and improving the quality of care. Evidence suggests that a wide range of psychological therapies including meditation, musictherapy, massage, cognitive-behavioral stress management are effective in stress control and reduction [13]. McFarland suggest strategies such as coping with teamwork, extracurricular activities, humor, positive feedback from managers, and participation in stress management programs have been helpful in reducing stress in nurses and doctors [14]. Douglas et al. have reported that nurses use techniques such as leisure activities, visiting friends and family and relaxation to cope with stressors [15]. An effective program for coping with stress is the life skill education based education (LSBE) [16]. Since 1993, a preventive program called LSBE has been performed to improve mental health and prevent psychosocial harms [17]. LSBE aims at prevention, control and management of problems [18]. A study by Tattle showed that LSBE can improve decision-making ability, sociability and self-confidence [19]. LSBE emphasizes coping skills, especially coping with stress because people are constantly exposed to stress, and if the source of stress is not controlled, the individual will be exposed to many physical and mental diseases [20]. LSBE contains ten skills; the most important being critical thinking. There are several definitions for critical thinking; the national council of critical thinking in 1996 considers it a systematic and rational process, in which, individuals actively and skillfully address conceptualization, application, analysis, integration and evaluation of data collected or produced, and progress toward belief and action through observation and experience, and interaction and reasoning [21]. Critical thinking is essential to medical sciences disciplines and should be included in all clinical training courses. Understanding process of critical thinking enhances nurses' efficacy in solving problems [22]. In fact, critical thinking is considered a complementary part [23] and a vital activity in nursing [22,24]. Based on the view expressed by the national association of nursing accreditation committee, stype asserts that nursing graduates are required to have problem-solving and critical thinking skills [25]. Moreover, the American association of nursing schools in 1998 and the educational principles guidelines for licensed professional clinical nurses have proposed critical thinking ability as an important expertise for students and graduates [26]. Critical thinking is considered an important aspect of professional function in nursing, midwifery and health, and a vital matter for nurses in clinical setting. As nursing has progressed from an occupation to a profession, the need for cognitive and communication skills has 
changed from duty-oriented nurses to nurses with advanced knowledge-based skills [27]. The increased complexity of patient care and accelerated changes in providing these cares demand development of care models in all stages from planning to implementation and evaluation [25]. To this end, not only should nurses acquire knowledge and skills, they but also should make judgments in critical clinical situations and make decisions to save a patient's life in complicated cases and thinking in critical situations [28]. Critical thinking provides nurses with a higher ability to analyze patient data, decide about their problems and associated possibilities, evaluate potential problems with the decision made, and make decisions in any situation [29]. Give the weakness of nurses in critical thinking (according to research), the importance of critical thinking in process of nursing, and the effect of stress control education on job satisfaction, researchers intend to assess the hypothesis of critical thinking education effectiveness on job satisfaction in psychiatric nurses.

\section{Method}

This experimental study was conducted on psychiatric nurses working in the hospitals in Mashhad, Iran in 2012. This hospital was chosen as the study setting for it size (the largest psychiatric hospital in the east of the country, with 750 active beds), being a teaching hospital, great number of studies conducted there, and familiarity and cooperation of nurses with research. Study inclusion criteria were willingness to participate, BSc (Bachelor of Science) or MSc (Master of Science) in nursing, working for at least six months in Ibn-Sina hospital, no use of psychotropic medication, no more than two weeks leave in the last month, poor critical thinking skill (score of less than 15.89). Study exclusion criteria were unwillingness to participate, absence in more than $10 \%$ of workshop time, leave or transfer to another hospital, and exposure to a major stress (death of relatives, divorce) in the course of study.
Arrangements were made with the education supervisor, and posters for enrollment in critical thinking workshop were posted in various hospital departments. Sixty nurses voluntarily enrolled for participation in the study. Participants were randomly divided into intervention (30 nurses) and control (30 nurses) groups according to their enrollment code (odd numbers intervention, and even numbers control). Due to withdrawal of 6 nurses (3 for non-participation in the workshop, 1 for sick leave, and 2 for incomplete questionnaires in the follow-up stage), eventually 54 nurses participated in the study (27 in each group). Tools used in this study included personal and occupational details form, critical thinking skills inventory, and Brayfield and Rothe Index of Job Satisfaction. The demographic questionnaire contained 16 items about personal and occupational details, and was prepared according to study objectives and review of the latest resources and articles. The California Critical Thinking Disposition Inventory (CCTDI) (form B) measures five critical thinking skills including interpretation, deductivereasoning, inductive reasoning, analysis, and evaluation, with 34 items and has been specifically designed to measure critical thinking in levels beyond high school. The overall score varies from 0 to 34 , with reported cut-off point of 15.89 . Thus, overall scores less than 15.89 indicate poor critical thinking skill and higher than 15.89 indicate strong critical skill [30]. Khodamoradi translated CCTDI into Persian and confirmed its validity and reliability [31]. In this study, content validity of this tool was confirmed by ten professors from Mahshad school of nursing and midwifery. Reliability of this tool was found for the first time by Khalili using internal consistency method, with Cronbach's alpha 0.62 [32]. In this study, reliability was found using internal consistency with Cronbach's alpha 0.73. In this study, participants had poor critical thinking scores (less than 15.89). The job satisfaction questionnaire contains 19 
items, and respondents are asked to identify their feeling and attitude toward their job according to a 5-point scale (totally disagree, disagree, undecided, agree, and totally agree). Items 5, 9, 7, 11, 12, 15, 17, and 19 are inversely scored. The overall score of this tool ranges from 19 to 95 . Higher overall scores indicate higher job satisfaction. Validity of this questionnaire was confirmed by ten experts from Mahshad School of Nursing and Midwifery. Reliability of the Persian version was found by Abdollahzadeh \& Kermorodi using internal consistency with Cronbach's alpha 0.93 [33]. In this study, reliability of job satisfaction questionnaire was found using internal consistency with Cronbach's alpha 0.88. Data were collected simultaneously from both groups before, one month after and two months after the intervention. Following approval by the Research Council of Mashahd university of medical sciences and the Ethics committee in 2012, critical thinking education began for the intervention group over two three-hour sessions with a week's interval, which included definition of critical thinking and its constituent processes, critical thinking in nursing and its importance in the process of nursing, fostering critical thinking capabilities in nurses, attributes of people with critical thinking, factors affecting critical thinking, barriers to critical thinking, advantages and results of critical thinking for nursing, researcher's lecture on activities and tasks, questions and answers, and group discussion. The control group received a lecture by the researcher on psychiatric signs and symptoms and common terminologies in Ibn-Sina hospital amphitheater over two three-hour sessions with a week's interval. Participants were assessed one and two months after the intervention. Over this period, the researcher contacted participants in the intervention group on the phone once every two weeks to follow-up and reinforce compliance with educational program. Data were analyzed in SPSS-19 software. Normal distribution of quantitative variables was confirmed using Kolmogorov-Smirnov test.
Demographic and personal details were described using mean, standard deviation, and percentages. Chi-square test was used to confirm the two groups matched in terms of qualitative variables, and normally distributed quantitative variables were compared using t-test (and Mann-Whitney test, if not normally distributed). T-test was also used to compare two groups in terms of occupational stress (and Mann-Whitney test, if not normally distributed). Repeated measures analysis of variance and Friedman test were used in intra-group comparison. All the above tests were performed at confidence interval $95 \%$ and significance level 0.05 .

\section{Results}

In this study, of the 54 participating nurses, $74.1 \%$ in the intervention group and $55.5 \%$ in the control were men, with mean age $33 \pm 4.1$ years. Of all participants, $85.2 \%$ from the intervention group and $77.7 \%$ from the control were married, and $96.3 \%$ in each group had BSc in nursing. Participants' mean psychiatric work experience was $6.8 \pm 4.4$ years. The majority of participants in both groups $(70.4 \%$ in the intervention group and $77.8 \%$ in the control) were in contract employment. The two groups matched in terms of all background variables, with no significant difference between them (Table 1). In the intervention group, mean and standard deviation of job satisfaction score increased from $62.5 \pm 7.6$ before intervention, to $66.8 \pm 6.4$ after intervention and $69.5 \pm 6.9$ in follow-up stage a month later. In the control group, mean job satisfaction score fell from $62.4 \pm 9$ before intervention, to $61.5 \pm 3.2$ after intervention and 58.5 \pm 9.6 in follow-up stage a month later. There was no significant difference between the two groups in terms of job satisfaction before intervention $(p=0.74)$. Independent t-test results showed a significant difference between the two groups in mean job satisfaction score after intervention, such that the intervention group score showed a significant increase compared to the control group (Table 2). 
Table 1 Demographic characteristics in teaching critical thinking and control

\begin{tabular}{|c|c|c|c|c|}
\hline \multirow{2}{*}{\multicolumn{2}{|c|}{ Variable }} & Control & Intervention & Test results \\
\hline & & $\mathrm{N}(\%)$ & N (\%) & \\
\hline \multirow{2}{*}{ Marriage } & Single & $4(14.8)$ & $6(22.3)$ & \multirow{2}{*}{$\begin{array}{c}\text { chisquare }=0.491 \\
\mathrm{df}=1 \\
\text { p-value }=0.484\end{array}$} \\
\hline & Married & $23(85.2)$ & $21(77.7)$ & \\
\hline \multirow{2}{*}{$\begin{array}{l}\text { Education } \\
\text { level }\end{array}$} & BS & $26(96.3)$ & $26(96.3)$ & \multirow{2}{*}{ fisher exact $=1.000$} \\
\hline & $\mathrm{Mc}$ & $1(3.7)$ & $1(3.7)$ & \\
\hline \multirow[t]{2}{*}{$\begin{array}{l}\text { Employment } \\
\text { status }\end{array}$} & Official & $8(29.6)$ & $6(22.2)$ & \multirow{2}{*}{$\begin{array}{c}\text { chisquare }=0.386 \\
\mathrm{df}=1 \\
\mathrm{p} \text {-value }=0.535\end{array}$} \\
\hline & Contractual & $19(70.4)$ & $21(77.8)$ & \\
\hline \multicolumn{2}{|c|}{ Age (years) } & $32 \pm 4.2$ & $33 \pm 4.1$ & $\begin{array}{c}\mathrm{t}=-0.412 \\
\mathrm{df}=52 \\
\mathrm{p} \text {-value }=0.682\end{array}$ \\
\hline
\end{tabular}

Table 2 Comparison of the mean score of nurses' job satisfaction in psychiatric wards in two groups before the intervention, one month after the intervention and follow-up two months later

\begin{tabular}{lccc} 
& Control & Intervention & Independent t-test \\
\hline & Mean \pm SD & Mean \pm SD & \\
\hline $\begin{array}{l}\text { Before } \\
\text { intervention }\end{array}$ & $9.0 \pm 62.4$ & $7.6 \pm 62.5$ & $\mathrm{p}=0.740$ \\
$\begin{array}{l}\text { A month after } \\
\text { intervention }\end{array}$ & $3.2 \pm 6.15$ & $6.4 \pm 66.8$ & $\mathrm{p}=0.020$ \\
$\begin{array}{l}\text { Followed two } \\
\text { months later }\end{array}$ & $9.6 \pm 5.85$ & $6.9 \pm 69.5$ & $\mathrm{p}=0.000$ \\
$\begin{array}{l}\text { Test result } \\
\text { variance with } \\
\text { repeated measures }\end{array}$ & $\mathrm{p}=0.000$ & $\mathrm{p}=0.000$ & \\
\hline
\end{tabular}

In the intervention group, comparing mean stress before, a month after and two months after intervention (intra-group comparison) using repeat measures ANOVA showed significant differences between three stages $(p=0.000)$. In the control group, repeat measures ANOVA results (intra-group comparison) showed significant differences in mean stress among the three stages before, a month after, and follow-up two months after $(\mathrm{p}=0.000)$. This test showed the difference among these stages $(\mathrm{p}=0.000)$.

\section{Discussion}

The results obtained showed significant improvement in mean job satisfaction score in the intervention group after intervention, indicating the positive effect of critical thinking education workshop on job satisfaction in psychiatric nurses. Since no similar study was found to compare the effect of critical thinking education on job satisfaction, the present study results were compared to those in studies that measured the effect of life skills or cognitive behavioral interventions on job satisfaction. In their study, Predfoot assessed the effect of cognitive-behavioral intervention on job satisfaction in employees of an insurance company in England, and their results showed a significant increase in mean job satisfaction score in the intervention group compared to the control following 7 intervention sessions [34].

In terms of the effect of cognitive-behavioral intervention on job satisfaction, their results agree with those obtained in the present study. Employees that feel greater inner strength and ability to risk feel greater jobs satisfaction, 
just as much [35]. Critical thinking education appears to have succeeded in this area. Manlovic \& Laschinger argue that job satisfaction can be improved in nurses through psychological empowerment of nursing personnel, and this will increase patient satisfaction and improve outcomes expected by patients [35]. In this study, the effect of stress immunization program on job satisfaction in nurses increased in the follow-up stage a month later compared to after intervention. This was probably due to the telephone contact made by the researcher to participants in the intervention group once every two weeks, in order to follow up and reinforce compliance with education program. Also, in the follow-up period, nurses had the opportunity to practice skills learnt in real life, and to internalize this program in their daily life by constant follow-up and practice, which led to increased effect of intervention over time. In their study, Durban et al. assessed the effect of stress immunization program on job satisfaction in psychiatric nurses. Their results showed significantly greater mean job satisfaction in the intervention group compared to the control after two intervention sessions [36], which agrees with the present study results.

Esmaeeli reported an increase from $9.36 \pm 2.7$ to $14.8 \pm 1.8$ in mean patient care in the intervention group after 9 days of critical thinking education in gastroenterology department, indicating effectiveness of critical thinking education [37], which agrees with the present study results.

The present study results showed that the least job satisfaction in the control group was in the follow-up stage, indicating reduced job satisfaction over time. This may be attributed to the reducing physical and mental strength of nurses every day, which adversely affected their job satisfaction. Teaching psychiatric symptoms and common terms to the control group participants had no effect on their job satisfaction. Hence, increased job satisfaction in the intervention group must have been due to the education they received.

\section{Conclusion}

In the healthcare system, nurses are the biggest health service providing group, and accordingly, they should have high levels of job satisfaction to enable them to provide quality patient care. This is possible when nurses are in a satisfactory mental state. Therefore, attention should be paid to nurses' health and job satisfaction to retain the nursing workforce as humans in the first place, and next as someone that protects health and well-being of other members of the community. The results showed that critical thinking education workshop can increase job satisfaction in nurses; it can therefore be used as a strategy for reducing occupational stress in nurses. In the present study, the most important limitations included; 1) small sample size and selection of participants from one hospital only, which limits generalizability of the results obtained; 2) personal differences, psychological characteristics, and personal and family attributes affecting answers to questions and effectiveness of workshop, which were matched in the two groups as much as possible through random allocation of participants to groups; 3 ) lack of complete control over information exchange between groups. To reduce spread of data, groups were matched in terms of their working shifts and post. Also, the intervention group was asked to refrain from spreading data until the end of study, and control group was assured of holding critical thinking workshop after the end of intervention; and in this way, exchange of data was largely controlled. However, it may have slightly occurred beyond control. It is recommended that similar studies be conducted in different parts of the country with a larger sample size.

\section{Acknowledgments}

We hereby thank all those that supported this study and paved the way for researchers.

\section{Contribution}

Study design: AH,AM

Data collection and analysis: AH, AM,PS

Manuscript preparation: AH, AM,PS 


\section{Conflict of Interest}

"The authors declare that they have no competing interests."

\section{Funding}

The author (s) received no financial support for the research, authorship and/or publication of this article.

\section{References}

1- Trevor M, Clinton M, Robinson S. Job satisfaction in nursing: validation of a new instrument for the UK. $J$ Nurs Manag2005; 13(4): 296-311.

2- Lu H, While AE, Barriball KL. Job satisfaction and its related factors: a questionnaire survey of hospital nurses in Mainland China. Inter J Nurs Stud2007; 44(4): 574-88.

3- Tallman R, Bruning NS. Hospital nurses' intentions to remain: exploring a northern context. Health Care Manag2005; 24(2): 32-43.

4- $\mathrm{Lu} \mathrm{H}$, While AE, Barriball KL. Job satisfaction among nurses: a literature review. Int J Nurs Stud2005; 42(3): 211-27.

5- Vaghar Seyyedin A, Porteghali P, Farokhfal Kh. Job satisfaction survey among nurses working in hospitals of Birjand university of medical sciences. Journal of Birjand University of Medical Sciences2005; 8(3-4): 16-21.

6- Akhtari Shojaee A, Nazari a, Vahidi R. The leadership styles used by managers and correlation whit nurses job satisfaction employing in educational and medical centers related to medicine university of Tabriz. Hakim Reseach Journal2004; 7(4): 20-5.

7- Moradi M. Effect of using improvement program for head nurses' management skills on the clinical competence of nurses in army hospital 501. [dissertation ] .st Nursing: Tarbiat Modares University 2007; pp: 252.

8- Lu H, While AE, Barriball KL. Job satisfaction among nurses: a literature review. Int J Nurs Stud2005; 42(2): 211-27.

9- Lauvrud C, Nostad K, Palmstierna T. Occurrence of post traumatic stress symptoms and their relationship to professional quality of life in nursing staff at a forensic psychiatric security unit:a cross-sectional. Health Qual Life Outcomes2009; 7(31): 1-6.

10 - Taylor B, Barling J. Identifying sources and effects of career fatigue and burnout for mental health nurses: A qualitative approach. Int J Ment Health Nurs2004; 13(4): 117-25.

11- Hannigan B, Edwards D. Burnout in community mental health nurses: findings from the all-wales stress study. J Psychiatr Ment Health Nurs2000; 7(2): 127-34. 12- Sutherland VJ, Cooper CL. Undrestanding stress: a psychological prespective for health professional . $J$ Stress Med; 7(3): 150-54.

13- Linden W. Stress manengment: from basic science to better practice. Philadelphia: SAGE publication; 2005. pp:83-5.

14- Mac Farlane D, Duff EM, Bailey EY. Coping with occupational stress in an accident and emergency department. West Indian Med J2004; 53(5): 242-7.

15- Duglas R. Job stress, Job performance and social support among hospital nurses. J Nurs Sch2004; 36(6): 73-8.

16- World Health Organazation. Skills for health: skills-based healtheducation including life skills: an important component of a child-friendly/ healthpromoting school. Geneva: WHO; 2003.

17- World Health Organization. Mental health action plan for Europe. Facing the challenges, building solutions. Geneva: WHO; 2005.

18-Aghajani R. The effectiveness of life skills training on mental health of children in school of Tehran [dissertation]. st psychology: Tehran: University of Allameh Tabatabaiee 2000; pp:196.

19- Tuttle J, Campbell-Heider N, David TM. Positive adolescent life skills training for high-risk teens: results of a a group intervention study. $J$ Pediatr Health Care2006; 20(3): 181-91.

20- George S, Jeffrey M. A clinical guide to the treatment of the human stress response. NewYork: Guilford press; 2013.

21-Sene A. Strategies for teaching critical thinking skills. Journal of Teacher Development2003(4); 22: 21-4.

22- Hosseini A, Bahrami M. Comparing the first and last year of undergraduate critical thinking in students. $J$ Med Edu2002; (6): 21-5.

23- Thompson C, Rebeschi LM. Critical thinking skill of baccalaureate at program entry and exit. Nur Health Care Prospect 1999; 20(5): 248-52.

24- Nekouei N, Pack Ghohar M, Khakbazan Z, Mahmoudi M. Evaluation of students' clinical decisionmaking. Journal Med Edu2002; (6): 49-54.

25- Staib Sh. Teaching and measuring critical thinking. J Nurs Educ2003; 42(11): 498-508.

26- Bekie T, Lowary L, Barnet L. Assesing critical thinking in baccalaureate nursing student. Holist Nurs Pract2001; 15(3): 18-26.

27- Hasanpour M, Haghdoost Oskouie SF, Salsalei M. Critical thinking in nursing education. Iran $J$ Nurs2005; 18(41-42): 7-16.

28- Youny ID. The important of critical thinking. $J$ Nurs Edu1998; 33(4): 153-4.

29- Oeman M. Critical thinking, critical practice. $J$ Nurs Manang1999; 30(4): 4.

30- Shin K, Sin S, Myoungs S. Critical thinking 
disposition and skill of senior nursing student in associate, baccalaureate, and RN to BSN programs. $J$ Nurs Edu2006; 75(6): 233-7.

31- Khodamoradi K, Saiodalzakerin M, Alavi Majed H, Yaghmaie F, Shahabi M. Translation and psychometric properties of California critical thinking skills test. Journal of Shahid Beheshti School of Nursing \& Midwifery2006; 16(55): 12-19.

32- Khalili H, Hosienzade M. Determine the validity, reliability and normative scores on the California critical thinking. Journal of Babol University of Medical Sciences2006;5(2):84-90.

33- Moghimi SM. Organization and research approach Management. Tehran: Termeh publication; 2007.

34- Proudfoot JP, Corr PJ, Guest DE, Dunn G. Cognitive-behavioural training to change attributional style improves employee well-being, job satisfaction, productivity, and turnover. Pers Individ Dif2009; 46(2): 147-53.

35- Newton JT, Gibbons DE. Levels of career satisfaction amongst dental healthcare professionals: comparison of dental therapists, dental hygienists and dental practitioners. Community Dent Health2001; 18(3): 172-6.

36- Darban F, Mazlom S. The effect of stress inoculation program on nurses' job satisfaction in psychiatric ward. J Nurs Manag2012; 1(2): 46-54.

37- Esmaili R, Izadi A, Esmaeili M, Omidy K. Effect of teaching critical thinking in nursing process of patient care. Journal of Birjand University of Medical Sciences2010;8(1),1-6. 